\title{
Twine selection is essential for successful hatchery cultivation of Saccharina latissima, seeded with either meiospores or juvenile sporophytes
}

\author{
Philip D. Kerrison ${ }^{1}$ D $\cdot$ Gail Twigg ${ }^{1} \cdot$ Michele Stanley $^{1} \cdot$ David De Smet $^{2} \cdot$ Guy Buyle $^{2} \cdot$ Adrián Martínez Pina $^{3} \cdot$ \\ Adam D. Hughes ${ }^{1}$
}

Received: 6 December 2018 / Revised and accepted: 19 March 2019 / Published online: 24 April 2019

(C) The Author(s) 2019

\begin{abstract}
The predominant method used for the cultivation of European kelp involves seeding onto twine spools. The selection of a suitable twine is essential. In four experiments, synthetic and natural polymer twines were seeded with either meiospore or juvenile sporophytes of Saccharina latissima. Development was monitored over both the hatchery and outplanting phase at an experiment seaweed farm, Scotland, UK. Twisted twine seeded with meiospores gave $37 \pm 21 \%$ higher biomass yield than the braided form, despite $46 \pm 10 \%$ lower sporophyte density during the hatchery period. Twisted twine was also more favourable when sporophyte seeding, increasing juvenile retention by $140 \%$. Three-month-old sporophytes had $50 \%$ weaker bioadhesion on polyamide (PA), polyester (PES) and polypropylene (PP) compared to polyvinyl alcohol (PVA). This was reflected in 11-24\% higher biomass on PVA following outplanting. However, if the twine surface was treated by corona discharge before seeding, PA, PES and PP achieved an equivalent biomass to PVA. Jute and sisal twine had a toxic effect on the development of meiospores. In contrast, seeding with sporophytes was successful onto jute and sisal, but bioadhesion was weak. Finally, cotton was moderately toxic to meiospores but also had a bioadhesion strength and biomass yield comparable to PVA. We conclude that PVA and corona-treated synthetic twines are excellent for either meiospore or sporophyte seeding. Cotton is a very promising biodegradable twine, although further research is needed to optimise its physical structure. We also conclude that results during the hatchery period do not predict the success of seeded twine following outplanting.
\end{abstract}

Keywords Saccharina latissima $\cdot$ Hatchery $\cdot$ Twine $\cdot$ Settlement $\cdot$ Cultivation $\cdot$ Corona

Electronic supplementary material The online version of this article (https://doi.org/10.1007/s10811-019-01793-x) contains supplementary material, which is available to authorized users.

Philip D. Kerrison

Philip.Kerrison@sams.ac.uk

Gail Twigg

Gail.Twigg@sams.ac.uk

Michele Stanley

Michele.Stanley@sams.ac.uk

David De Smet

David.DeSmet@centexbel.be

Guy Buyle

Guy.Buyle@centexbel.be
Adrián Martínez Pina

Adrian@tecnored.es

Adam D. Hughes

Adam.Hughes@sams.ac.uk

1 Scottish Association for Marine Science (SAMS), University of the Highlands and Islands (UHI) Scottish Marine Institute, Dunbeg, Argyll PA37 1QA, UK

2 Centexbel Gent, Technologiepark 7,Zwijnaarde, 9052 Ghent, Belgium

3 Tecnología redera, S.L, Poligono Industrial s/n, 03350 Cox. Alicante, Spain 


\section{Introduction}

The cultivation of phaeophyte macroalgae is becoming established in Europe. Saccharina latissima is a fastgrowing species that is currently cultivated across the region from the Faroes Islands, to Norway and Spain (Peteiro and Freire 2011; Forbord et al. 2012; Bak et al. 2018). The main markets are currently food and health supplements; although, it also has an application for bioactives, feed, carbon sequestration and conversion to a biofuel (Holdt and Kraan 2011; Hughes et al. 2012; Kraan 2013; Bleakley and Hayes 2017). The predominate method in Europe for the cultivation of kelps involves seeding meiospores (n) or gametophyte stocks (n) onto spools carrying twine ( $\varnothing 1-6 \mathrm{~mm})$. The twine is then cultured in a hatchery until dense overages of 2 to $10-\mathrm{mm}$ juvenile sporophytes $(2 \mathrm{n})$ are visible after 6-12 weeks (Forbord et al. 2012; Kerrison et al. 2016). The spools are then outplanted to a seaweed farm site, where the twine is wound around a larger diameter rope and left for 4-8 months to grow to adult size.

A variety of different twines have been reported for kelp cultivation across Europe, including polyamide (PA), polypropylene (PP), polyester (PES), polyvinylalcohol (PVA) and cotton in twisted or braided forms (Druehl et al. 1988; Edwards and Watson 2011; Werner and Dring 2011; Sanderson et al. 2012; Peteiro et al. 2014). Yet, there is little published data comparing the effectiveness and suitability of different twine materials (Holt 1984; Salinas et al. 2006). It is now known that differences in surface chemistry between polymers can strongly influence meiospore settlement behaviour and sporophyte attachment success in S. latissima (Kerrison et al. 2017, 2018a) similar to reports in other marine organisms (Rittschof and Costlow 1989; Huggett et al. 2009). Specifically, the cross-linked alginate-polyphenol bioadhesive system of the Phaeophyceae (Bitton et al. 2006; Salgado et al. $2009)$ does not bond well to high water contact angle $\left(\theta_{\mathrm{w}}\right)$ materials, such as PP (Kerrison et al. 2018a). This can lead to detachment from the surface when the sporophytes reach a few centimetres in length and experience increased drag due to the higher Reynold's number environment (Vogel 1996; Kerrison et al. 2017). Surface modification using corona discharge can reduce the $\theta_{\mathrm{w}}$ of synthetic polymers such as PP (Süzer et al. 1999) and improve bioadhesion in S. latissima (Kerrison et al. 2018a). Thus, corona may be a feasible method to create an improved attachment surface for macroalgae on various synthetic polymers.

Macroscopic surface roughness is another important factor in the successful attachment of marine organisms (Candries et al. 2001). A varied topography allows the mechanical interlocking of the holdfast bioadhesive and/or hapteron with the surface (Milligan and DeWreede 2000). This thigmotactic interaction will allow mechanical attachment even where there is only weak chemical bioadhesion. Thus, mechanical interlocking onto surface roughness may supersede the need for chemical compatibility between the bioadhesive and surface chemistry during twine seeding. The success of attachment may then be modulated by the choice of either braided or twisted twine, which provides a different local topographical landscape for the developing juvenile (Salinas et al. 2006).

The problem of oceanic plastic pollution is becoming increasingly prominent in the public conscience. The abrasion of synthetic twines and ropes used by the fishing and aquaculture industries is an substantial source of small- or microplastic fibres (Gewert et al. 2017) which can impact marine organisms (Wright et al. 2013). The selection of renewable biodegradable polymer is recommended for the fledging European macroalgal cultivation industry to ensure its green credentials are maintained, similar to in other marine industries (Winger et al. 2015).

A new method under development for seeding kelp is to use juvenile sporophytes $(0.1-2 \mathrm{~mm})$ embedded within a hydrocolloid binder (Kerrison et al. 2018b). This binder method allows direct seeding onto substrates immediately prior to submersion in the sea, but may also be used to seed onto twine within the hatchery. It is hypothesised that the contrasting size and development stage of the juvenile sporophytes compared to single-celled meiospores $(\varnothing 8 \mu \mathrm{m})$ will result in different optimal twine characteristics.

The aim of this study is to determine how the character of the twine selected for the hatchery phase can influence cultivation success, in the hatchery and after outplanting at a seaweed farm. Through four stepwise experiments, we assess the suitability of the following: (1) four synthetic polymer twine chemistries (PA, PES, PP and PVA), (2) the braided and twisted form, (3) surface modification by corona discharge, (3) three nature polymer twines (cotton, jute and sisal) and (4) seeding with either meiospores or sporophytes.

\section{Methods}

Synthetic twines ( $\varnothing$ ca. $2 \mathrm{~mm}$ ) of polyamide (PA), polyester (PES), polypropylene (PP) and polyvinylalcohol (PVA) were prepared in both braided and twisted forms (Tecnored, ES; Sioen Industries NV, BE; Supp. Table 1). Three natural fibre twines (cotton, jute and sisal; $\varnothing \sim 2 \mathrm{~mm}$ ) were also sourced separately (Homebase, UK).

In experiment 1 (E1), each twine was wound to tightly cover a glass microscopic slide pre-cleaned with a $24 \mathrm{~h}$ soak in 5\% Decon 90 detergent (Decon Laboratories Ltd., UK), $24 \mathrm{~h}$ in $10 \%$ hydrochloric acid, rinsed in ultra-high purity water and dried at $40^{\circ} \mathrm{C}$. The wound twine slides were soaked $24 \mathrm{~h}$ in $2 \%$ sodium bicarbonate solution, rinsed thoroughly, soaked for a further $24 \mathrm{~h}$ in ultra-high purity water and dried at $40{ }^{\circ} \mathrm{C}$. This procedure will remove manufacturing residues and dirt, which can influence the settlement and attachment 
response of marine organisms. Meiospores were extracted from five fertile specimens of $S$. latissima, as described previously (Kerrison et al. 2016). Briefly, sporangial tissue was wiped clean, excised and dried overnight in a refrigerator at $4{ }^{\circ} \mathrm{C}$. They were submerged in $8.5^{\circ} \mathrm{C}$ tyndallized seawater (Kawachi and Noël 2005), enriched with F/2 medium without silicate $(\mathrm{F} / 2-\mathrm{Si})$. These were incubated in the dark for $1 \mathrm{~h}$ with agitation every $15 \mathrm{~min}$. The meiospore suspension was then filtered at $50 \mu \mathrm{m}$ and enumerated using a Sedgwick Rafter counting chamber.

Twine slides were submerged within independent borosilicate glass basins $(n=5)$ containing $150 \mathrm{~mL}$ of $8.5^{\circ} \mathrm{C} \mathrm{F} / 2-\mathrm{Si}$ and $0.125 \mathrm{~mL}$ saturated germanium dioxide solution $\cdot \mathrm{L}^{-1}$ (Kerrison et al. 2016) and shaken to remove air bubbles. Glass slides alone were used as the control $(n=5)$. One hundred thousand meiospores were introduced into each basin and incubated $48 \mathrm{~h}$ in the dark at $8.5^{\circ} \mathrm{C}$. The twine slides were then transferred to basins containing $150 \mathrm{~mL}$ of fresh medium and were incubated at 15-25 $\mu$ mol photons. $\mathrm{m}^{-2} \mathrm{~s}^{-1}, 12: 12 \mathrm{~L}: \mathrm{D}$ under warm white fluorescent lighting with gentle bubbling. Every 7 days, thereafter, the lighting was increased to $30-50 \mu \mathrm{mol}$ photons $\cdot \mathrm{m}^{-2} \mathrm{~s}^{-1}$ and the twines were transferred to new basins of $\mathrm{F} / 2-\mathrm{Si}$, without $\mathrm{GeO}_{2}$ until week 6 , following the recommendations of Kerrison et al. (2016).

In experiment 2 (E2), a set of PA, PES, PP and PVA twisted twine was passed five times, through a $1000 \mathrm{~W}$ corona treater (Ahlbrandt Systems, GE) at $2 \mathrm{~m} \mathrm{~min}^{-1}$. Both corona-treated and untreated twines were wrapped tightly around the centre of pre-cleaned glass slides to cover $\sim 20 \mathrm{~mm}$; this was due to limited availability of corona treated twine. All twine slides were then cleaned, seeded and incubated as described above, except that they were maintained at $15-25 \mu \mathrm{mol}$ photons. $\mathrm{m}^{-2} \mathrm{~s}^{-1}$ through the entire 6-week cultivation and not bubbled. After 4 weeks, duplicate slide sections $\left(37.2 \mathrm{~mm}^{2}\right)$ were photographed using stereomicroscopy allowing the apparent sporophyte density and the length of the five largest sporophytes to be determined using Image J 1.46r (National Institutes of Health, USA). After 6 weeks, the entire slide was photographed to determine the length of the five largest sporophytes and to estimate the sporophyte coverage (\%).

At the end of E1 and E2, the twine was removed from the slide and wrapped around $1-\mathrm{m}$ length of PES rope $(\varnothing 8 \mathrm{~mm}$; Bexco NV-SA, BE). For experiment 3 (E3), these 1-m ropes were deployed at the Sound of Kerrera experimental seaweed farm, Scotland $\left(56.3820^{\circ} \mathrm{N}, 5.5370^{\circ} \mathrm{E}\right)$, on 23 March 2015 to monitor their grow-out. The ropes were mounted in a randomised order on a ladder system, $1 \mathrm{~m}$ apart at a depth of $1.5 \mathrm{~m}$ (Supp. Fig. 1). The lines were harvested after 5 months (13 August 2015). The length of the five largest fronds was recorded, and the fresh mass of the section recorded after water was shaken off for $30 \mathrm{~s}$.

In experiment $4(\mathrm{E} 4)$, twine slides were prepared and cleaned as in E1. These were seeded with a sporophyte culture at a density of 10 sporophytes $\mathrm{cm}^{-2}$ in a $2 \%$ BinderA hydrocolloid solution (SAMS, UK). The cultures were then maintained as in E1. After 5 weeks, a photograph of each slide was used to determine the apparent sporophyte density. The twines were then suspended, $10 \mathrm{~cm}$ apart and $5 \mathrm{~cm}$ above the bottom of outdoor tanks $2.6 \times 0.6 \times 0.5 \mathrm{~m}$, which received a constant flow of sand-filtered natural seawater. After 3 months, individual sporophytes with no interaction to neighbours were selected for detachment force trials following the protocol in Kerrison et al. (2018a). Briefly, a digital force gauge (FK25,
Fig. 1 a Density of Saccharina latissima sporophytes in experiment 1. a Four weeks after seeding from meiospores onto different twine materials and $\mathbf{b}$ visually estimated coverage $5 \mathrm{wk}$ after seeding. Five synthetic twines were examined in both braided (cross-hatched) and twisted (hatched) forms: polyamide (PA), two polyester twines $\left(\mathrm{PES}_{1}\right.$ and $\mathrm{PES}_{2}$ ), polypropylene (PP) and polyvinylalcohol (PVA). Significant difference between braided and twisted pairs are shown $* P<0.05, * * P<0.01$. Three natural fibre twines were also examined: cotton $(\mathrm{C})$, jute $(\mathrm{J})$ and sisal (S). A glass microscopic slide $(\mathrm{G})$ was used as a control. Shown is mean \pm standard deviation
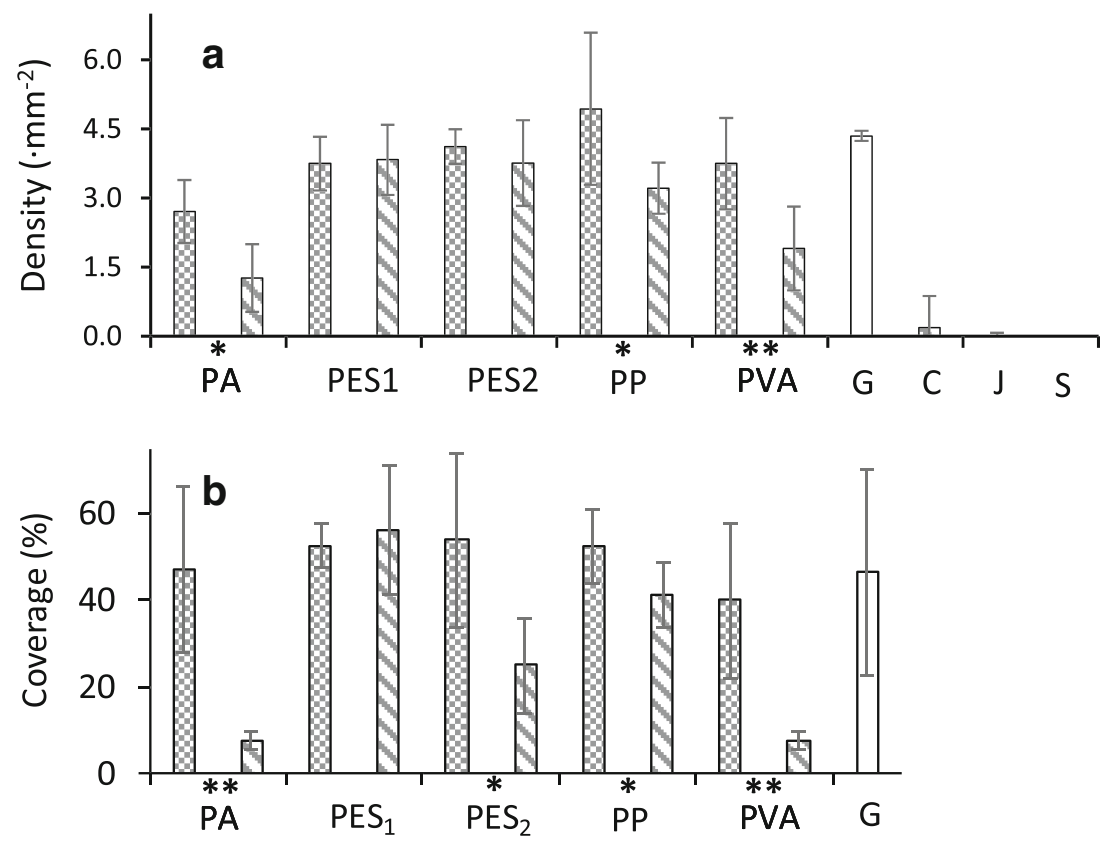
Sauter, DE) was clipped to the base of the frond $(>10 \mathrm{~mm})$ and pulled perpendicular to the twine until either the sporophyte detached or broke. Six replicates were completed for each twine, where present, and the morphological characteristics of these sporophytes recorded: frond length, width, stipe length, and length of three largest hapterae.

\section{Statistics}

Before analysis, all data were log transformed and tested for normality (Anderson and Darling 1952) and homoscedasticity (Levene 1960). Significant differences were tested using oneor two-way analysis of variance (AN, $2 \mathrm{wAN}$ ), followed by post hoc Fisher's (phF) to examine individual differences between treatments. Excel 2016 (Microsoft Corp., USA) and Minitab 15.1.0.0 (LEAD Technologies, Inc., USA) were used for all statistical analyses.

\section{Results}

\section{Experiment 1 (E1): material selection when seeding with meiospores}

After 4 weeks, the glass slide control had a sporophyte density of $4.35 \pm 0.68 \mathrm{~mm}^{-2}$ with mean maximum length of $0.97 \pm$ $0.25 \mathrm{~mm}$. The natural fibre materials adversely affected the meiospore survival and/or development compared to the control (all $P<0.001$ ): no sporophytes were apparent on either jute or sisal (Supp. Fig. 2), while only a very low density $\left(0.19 \pm 0.07 \mathrm{~mm}^{-2}\right)$ of small sporophytes $(0.04 \pm 0.03 \mathrm{~mm})$ was present on cotton (Fig. 1a; Table 1). On the five synthetic twines examined, the sporophyte length after 4 weeks was not significantly affected by polymer choice or the braided/ twisted form (Table $1 ; P>0.05$ ), with the exception of twisted PA where the sporophytes were $50 \%$ smaller than on the glass control $(p H-F P<0.05)$. Conversely, the sporophyte density after 4 weeks was significantly affected by the choice of polymer ( 2 wAN, $F_{4,1,4,30}=8.7 ; P<0.0001$ ), with a $50 \%$ lower density on PA $\left(p H-F, P<0.05 ; 1.98 \pm 0.99 \mathrm{~mm}^{-2}\right)$ and $35 \%$ lower density on PVA, although this was not significant $\left(P>0.05 ; 2.83 \pm 1.15 \mathrm{~mm}^{-2}\right)$. Twisted twine resulted in significantly lower sporophyte densities ( $2 \mathrm{wAN}, F_{4,1,4,30}=15.3$; $P<0.0001)$. PA, PP and PVA twisted twine had $46 \pm 10 \%$ fewer sporophytes. The exception was on PES twine where no difference was seen $(P>0.05$; Fig. $1 \mathrm{~b})$.

After 5 weeks, the sporophyte mean maximum length was still not significantly affected by the synthetic polymer choice or braided/twisted form $(P>0.05$; Table 1). Conversely, the sporophyte coverage was significantly affected by both the polymer choice ( $2 \mathrm{wAN}, F_{4,1,430}=7.2 ; P<0.0001$ ) and braided/twisted (2wAN, $\left.F_{4,1,4,30}=35.2 ; P<0.0001\right)$, with a significant interaction $\left(2 \mathrm{wAN}, F_{4,1,430}=5.3 ; P<0.005\right)$. Braided materials were
Table 1 Mean maximum length of Saccharina latissima sporophytes on different twine 4-6 wk. after meiospore seeding in the laboratory (experiments 1 and 2), and 5 mo after seeding following outplanting at a seaweed farm (experiment 3 ). Shown is mean \pm standard deviation

\begin{tabular}{|c|c|c|c|c|}
\hline & \multirow[b]{2}{*}{ Polymer } & \multicolumn{2}{|c|}{ Length (mm) } & \multirow{2}{*}{$\begin{array}{l}\text { Length }(\mathrm{cm}) \\
\text { Ca. } 5 \text { mo }\end{array}$} \\
\hline & & $4 \mathrm{wk}$ & $5 / 6 \mathrm{wk}$ & \\
\hline \multirow[t]{14}{*}{ Experiment 1} & $\mathrm{PA} \mathrm{Br}$ & $0.82 \pm 0.13$ & $3.07 \pm 0.67$ & $103 \pm 11$ \\
\hline & PA Tw & $0.48 \pm 0.13$ & $2.46 \pm 0.73$ & $108 \pm 11$ \\
\hline & $\mathrm{PES}_{1} \mathrm{Br}$ & $0.82 \pm 0.12$ & $3.13 \pm 0.60$ & $100 \pm 15$ \\
\hline & $\mathrm{PES}_{1} \mathrm{Tw}$ & $0.72 \pm 0.12$ & $3.19 \pm 0.52$ & $114 \pm 12$ \\
\hline & $\mathrm{PES}_{2} \mathrm{Br}$ & $0.83 \pm 0.18$ & $4.09 \pm 1.29$ & n.t. \\
\hline & $\mathrm{PES}_{2} \mathrm{Tw}$ & $0.78 \pm 0.17$ & $3.55 \pm 0.29$ & n.t. \\
\hline & $\mathrm{PP} \mathrm{Br}$ & $0.83 \pm 0.10$ & $3.59 \pm 0.34$ & $110 \pm 5$ \\
\hline & PP Tw & $0.83 \pm 0.16$ & $4.17 \pm 1.38$ & $104 \pm 2$ \\
\hline & PVA Br & $0.86 \pm 0.22$ & $4.28 \pm 1.12$ & $113 \pm 12$ \\
\hline & PVA Tw & $0.71 \pm 0.12$ & $3.76 \pm 0.50$ & $106 \pm 5$ \\
\hline & Glass & $0.97 \pm 0.25$ & $3.87 \pm 1.62$ & n.t. \\
\hline & Cotton & $0.04 \pm 0.03$ & n.t. & $115 \pm 6$ \\
\hline & Jute & n.d. & n.t. & n.t. \\
\hline & Sisal & n.d. & n.t. & n.t. \\
\hline \multirow[t]{8}{*}{ Experiment 2} & PA Tw & $0.44 \pm 0.09$ & $2.69 \pm 0.78$ & $103 \pm 4$ \\
\hline & PA Twe & $0.45 \pm 0.07$ & $2.53 \pm 0.53$ & $106 \pm 4$ \\
\hline & PES Tw & $0.36 \pm 0.11$ & $2.48 \pm 0.35$ & $104 \pm 6$ \\
\hline & PES Twc & $0.42 \pm 0.04$ & $2.60 \pm 0.62$ & $104 \pm 3$ \\
\hline & PP Tw & $0.46 \pm 0.07$ & $2.20 \pm 0.21$ & $98 \pm 4$ \\
\hline & PP Twc & $0.42 \pm 0.11$ & $2.69 \pm 0.30$ & $105 \pm 5$ \\
\hline & PVA Tw & $0.36 \pm 0.10$ & $2.32 \pm 0.69$ & $108 \pm 11$ \\
\hline & PVA Twe & $0.28 \pm 0.04$ & $2.84 \pm 0.31$ & $107 \pm 6$ \\
\hline
\end{tabular}

$P A$ polyamide, $P E S_{1} / P E S_{2}$ polyester from different suppliers, $P P$ polypropylene, $P V A$ polyvinylalcohol, $B r$ braided, $T w$ twisted, $c$ corona-treated, $n . d$. not detected, n.t. not tested

not significantly different from the glass control $(P>0.05)$, while twisted materials had significantly lower coverage on all materials (AN, $F_{1,6}=6.3-26.4 ; P<0.01-0.05$ ) except $\mathrm{PES}_{1}$ $(P>0.05)$. The difference between braided and twisted forms was $81-87 \%$ on PA and PVA, $53 \%$ on $\mathrm{PES}_{2}$ and $21 \%$ on PP. Data was not collected from the natural polymers due to negligible coverage visible.

\section{Experiment 2 (E2): corona twines with meiospore seeding}

After 4 weeks of growth, a significant difference was seen in both the mean maximum length and the density of sporophytes on the four synthetic polymers ( 2 wAN, $F_{1,3,3,24}=4.4-14.4 ; P<0.05$ $0.0001)$. In both cases, this was due to PVA, where the sporophytes were $25 \%$ smaller (Table 1; $0.32 \pm 0.08 \mathrm{~mm}$ ) and $56 \%$ less numerous (Fig. 2a; $2.96 \pm 0.77 \mathrm{~mm}^{-2}$ ) than on the other materials $\left(0.43 \pm 0.08 \mathrm{~mm}\right.$ and $6.68 \pm 1.55 \mathrm{~mm}^{-2}$; Supp. Fig. 3). 

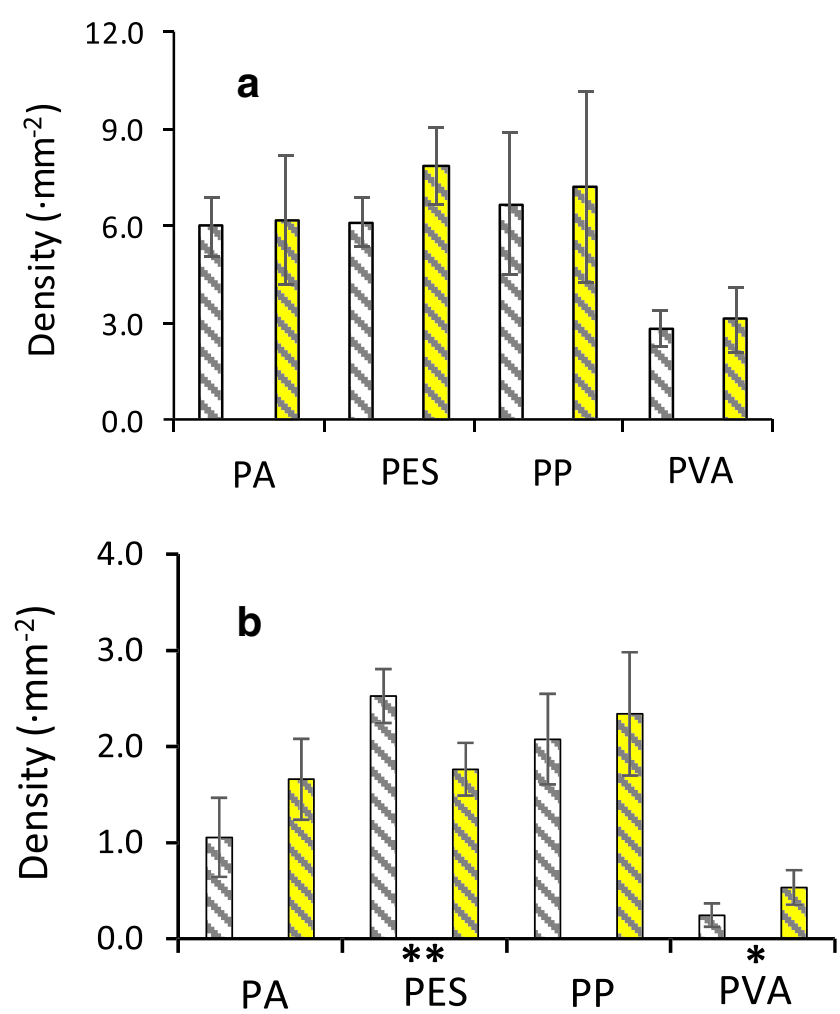

Fig. 2 Density of Saccharina latissima sporophytes on four synthetic twisted twines (hatched) in experiment 2. a Four weeks or b 6 wk. following meiospore seeding: polyamide (PA), polyester (PES), polypropylene (PP) and polyvinylalcohol (PVA). Untreated (white) and corona treated (shaded) twine is compared and significant difference between these pairs are shown as $* P<0.05, * * P<0.01$. Shown is mean \pm standard deviation

After 6 weeks, all twines had a similar mean maximum length $(P>0.05)$ of $2.54 \pm 0.49 \mathrm{~mm}$. The sporophyte density was still significantly affected by polymer type (Fig. 2b; 2 wAN, $\left.F_{1,3,3,24}=39.2 ; P<0.001\right)$. Highest density was seen on PP and PES $\left(2.18 \pm 0.49 \mathrm{~mm}^{-2}\right)$, with less seen on PA $\left(1.36 \pm 0.50 \mathrm{~mm}^{-2}\right)$ and PVA $\left(0.39 \pm 0.21 \mathrm{~mm}^{-2}\right)$. Corona treatment alone did not affect the density $(P>0.05)$; however, there was a significant interaction with a higher density seen on corona-treated PVA $\left(+120 \%\right.$; AN, $\left.F_{1,6}=7.1 ; P<0.05\right)$ and lower density on treated PES $\left(-30 \%\right.$; AN, $F_{1,6}=15.2$; $P<0.01)$.

\section{Experiment 3 (E3): outplanted polymer and corona twines}

All treatments from the polymer twine experiment (E1) reached a mean maximum length of $107 \pm 10 \mathrm{~cm}$ with no significant effect of twisted/braided or polymer $(P>0.05$; Table 1). However, the final fresh mass was affected due to twisting/braiding ( 2 wAN, $F_{3, \mathbf{1}, 3,24}=12.1 ; P<0.005$ ), with twisting increasing it by $37 \pm 21 \%$ from $4.5 \pm 0.7$ to $6.1 \pm$ $0.3 \mathrm{~kg}$ (Fig. 3a). There was no significant influence of polymer on the final fresh mass or any interaction $(P>0.05)$.
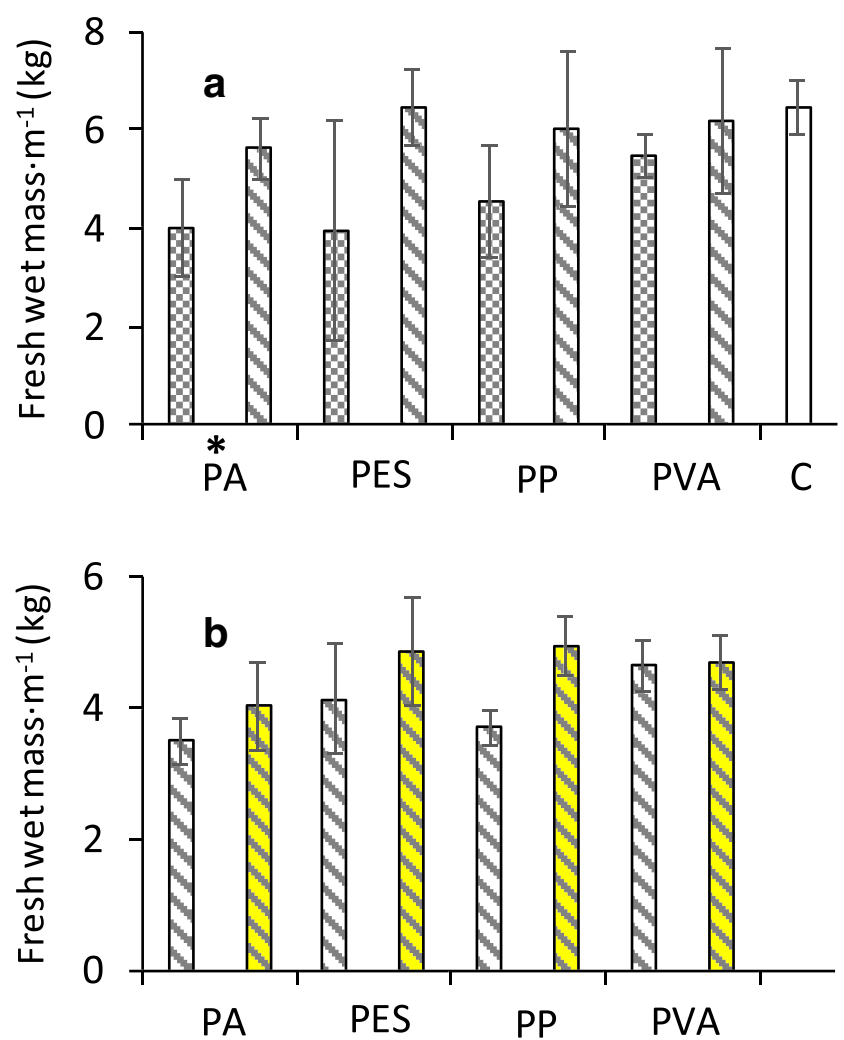

Fig. 3 Fresh wet mass of Saccharina latissima harvested from different meiospore seeded twines at the Kerrera experimental seaweed farm, Scotland, after ca. 5 mo of growth. a Braided (cross-hatched) and twisted (hatched) variants of PA, PES, PP, and PVA, as well as cotton (C) twine. b Untreated, twisted twine (white hatched) or corona treated, twisted twine (shaded and cross-hatched). Significant difference between pairs is shown as $* P<0.05$. Shown is mean \pm standard deviation

All treatments from the corona twine experiment (E2) treatments reached a mean maximum length of $104 \pm 6 \mathrm{~cm}$ with no significant effect of polymer or corona $(P>0.05$; Table 1$)$. The final fresh mass was increased by the corona treatment ( 2 wAN, $F_{3,1,3,24}=10.2 ; P<0.01 ;$ Fig. $\left.3 b\right)$ and varied with the polymer type ( $2 \mathrm{wAN}, F_{3,1,3,24}=3.9 ; P<0.05$ ). The largest increase in fresh mass due to corona treatment was $34 \%$ on PP: $3.7 \pm 0.3$ to $5.0 \pm 0.5 \mathrm{~kg}$. The smallest increase of $15 \%$ was seen on PA: $3.5 \pm 0.3$ to $4.0 \pm 0.7 \mathrm{~kg}$. PVA was equally effective with or without the corona treatment $(4.7 \pm 0.5 \mathrm{~kg}$; $P>0.05)$.

\section{Experiment 4 (E4): material selection with sporophyte seeding}

When twine was seeded using sporophytes, a significant difference in sporophyte density was seen due to polymer choice (AN, $F_{7,28}=2.7 ; P<0.05$ ) and the braided/twisted forms ( 2 wAN, $F_{5,1,5,12}=12.5 ; P<0.005$; Fig. $4 a$ ). Surface roughness was observed to influence the sporophyte density. The smooth glass control had a sporophyte density similar to the braided twines $\left(1.3 \pm 0.5 \mathrm{~cm}^{-2} ; P>0.05\right)$, whereas the 

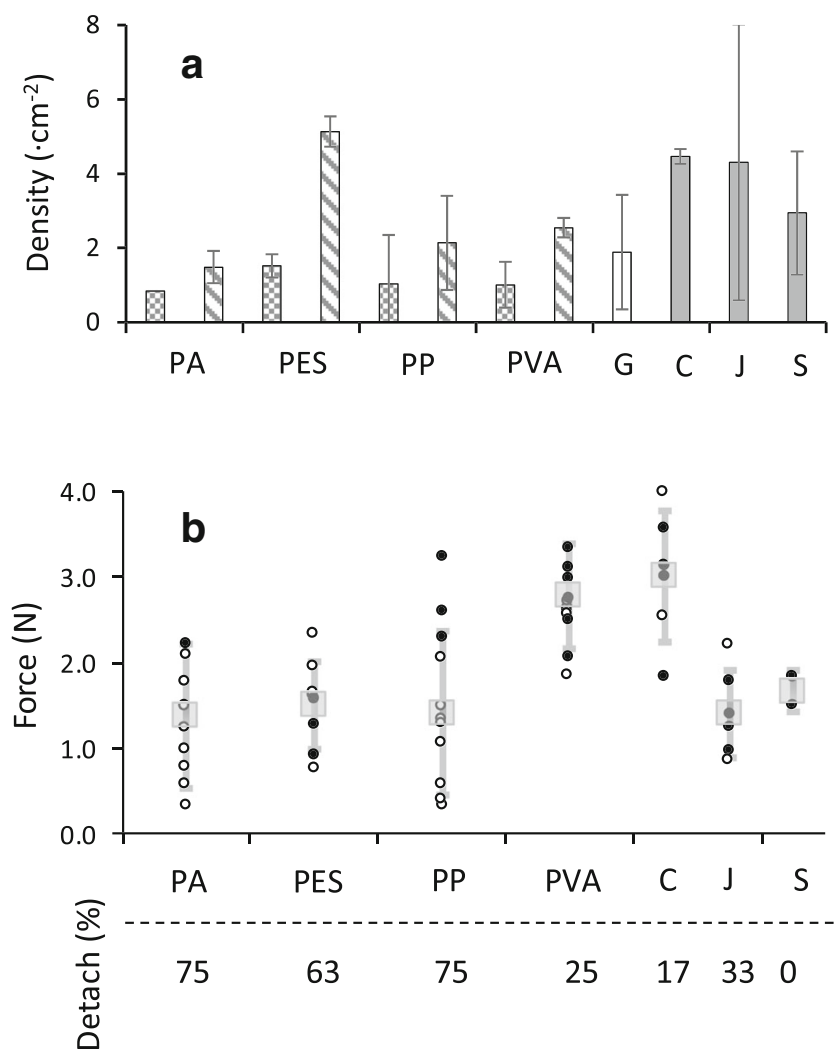

Fig. 4 a Density of Saccharina latissima sporophytes on different polymer twines $5 \mathrm{wk}$. following sporophyte seeding. Synthetic polymers tested were polyamide (PA), polyester (PES), polypropylene (PP) and polyvinylalcohol (PVA). Natural polymer twines tested were cotton $(C)$, jute $(J)$ and sisal (S). A glass microscopic slide $(\mathrm{G})$ was used as a control. Shown is mean \pm standard deviation. b Attachment force of the individual sporophytes 4 months following seeding (length $160 \pm$ $50 \mathrm{~mm}$ ). White circles denote the force at which the holdfast detached; black circles denote breakage of the sporophyte before detachment. Shown in grey is mean \pm standard deviation

sporophyte density was high on both twisted twine $(2.8 \pm 1.7$ $\left.\mathrm{cm}^{-2}\right)$ and the natural fibres $\left(3.9 \pm 2.2 \mathrm{~cm}^{-2}\right)$.

Juvenile sporophyte detachment force was not affected by braided/twisted polymer form $(P>0.05)$; however, there was a significant difference between the polymers tested (AN, $\left.F_{5,50}=8.2 ; P<0.0001\right)$. The greatest attachment force of $2.85 \pm 0.65 \mathrm{~N}$ was seen on PVA and cotton, whereas all other materials had an attachment force of $1.43 \pm 0.74 \mathrm{~N}$; Fig. 4b). Only two samples were tested for sisal, and so, it could not be tested for significance.

During the attachment force test, about half of the sporophytes broke at the stipe or frond rather than detach from the twine. Detachment occurred most often (63-75\%) on the synthetic polymers PA, PES and PP, but only $17-33 \%$ on PVA, cotton and jute. The force required for detachment of the holdfast $(1.42 \pm 0.85 \mathrm{~N})$ was significantly lower that the force at which the sporophyte broke $\left(2.37 \pm 0.85 \mathrm{~N} ; \mathrm{AN}, F_{1,56}=\right.$ $18.3 ; P<0.0001)$. No pattern was seen regarding detachment force and the sporophyte morphological parameters $(P>0.05$; Supp. Table 2).

\section{Discussion}

We report very large differences in the suitability of twine, depending on numerous factors including: polymer chemistry, natural or synthetic, twisted or braided, corona treatment and the developmental stage used for seeding. These results are applicable to both researchers and commercial cultivators.

\section{Synthetic twines}

Meiospore-seeded twines of PP, PES and PA all produced a dense coverage of sporophytes in the hatchery phase (1-4 sporophyte $\cdot \mathrm{mm}^{-2}$ ), and produced a yield of $4-6 \mathrm{~kg} \mathrm{~m}^{-1}$ at harvest. In contrast, smooth films of PP and PES have been found to be incompatible with the holdfast bioadhesive, leading to their eventual detachment (Kerrison et al. 2018a). The successful seeding and harvest of PP and PES twines in this study shows the importance of mechanical interlocking to the attachment of $S$. latissima, similar to natural kelp on rocks (Milligan and DeWreede 2000): the thigmotactic interlocking of the holdfast with the surface structure of the twine has superseded the need for a strong chemical bioadhesion.

Despite mechanical attachment being highly effective, the surface chemistry still has a role. The attachment force of sporophytes grown on PVA was twice that on PP, PES and PA and resulted in an increased final yield of $11-24 \%$. PVA is widely used for macroalgal cultivation in SE Asia (Werner and Dring 2011; Kuraway 2015) and has recently been validated as ideal for bioadhesion of Phaeophyceae macroalgae (Kerrison et al. 2019). The strong chemical interaction of the holdfast bioadhesive with PVA decreases the likelihood of juvenile detachment and so maximises the final yield achieved through cultivation. Strong bioadhesion will also increase the reliability of cultivation, as it will decrease the risk of juvenile detachment, for example, due to abrasion against the carrier rope or turbulence during storms.

\section{Hatchery studies do not inform us about success at sea}

We have determined that it is not possible to extrapolate the performance of small sporophytes in the hatchery, to their final yield after outplanting. Firstly, as reported in Kerrison et al. (2019), meiospore settlement tends to be higher on high $\theta_{\mathrm{w}}$ materials and lower at low $\theta_{\mathrm{w}}$. This favours a higher initial density on materials that are less suitable for sporophyte attachment, because the Phaeophyceae bioadhesive (Bitton et al. 2006) does not bond well to surfaces with a low $\theta_{\mathrm{w}}$ (Kerrison et al. 2019). Broadly, this is the pattern we observe, 
with a lower sporophyte density on PVA $\left(\theta_{\mathrm{w}} 70^{\circ}\right)$ compared to PP $\left(\theta_{\mathrm{w}} 102^{\circ}\right)$. Secondly, the flow environment inhabited by the juveniles and the adults is very different. Small sporophytes of kelp $(<1 \mathrm{~cm})$ grow in a viscous-dominated, low Reynold's number condition (Vogel 1996), and so remain attached despite weak bioadhesion (Kerrison et al. 2017). Yet, with a weak attachment, they can be easily detached due to abrasion or drag as they grow larger and experience the more turbulent environment of higher Reynold's numbers (Kerrison et al. 2018, 2019). This is a very important in the context of hatchery cultivation, as a dense coverage of juveniles is not a guarantee that once outplanted a high yield will be achieved. A twine with a lower sporophyte density and patchy growth in the hatchery can give a higher yield (e.g., comparing PVA and PP in E3). To draw reliable conclusions, future hatchery studies should ensure that the adhesion of juvenile seaweed is challenged using either pull tests, high velocity water jets or physical abrasion (Finlay et al. 2002; Kerrison et al. 2018a).

\section{Toxic leachates, additives and cleaning the twine}

During the manufacture of synthetic polymers, complex additive mixtures are incorporated to alter the characteristics of the final product, including the colour, flexibility and degradability (Deanin 1975). These additives can modulate macroalgal bioadhesion by altering the surface chemistry (Kerrison et al. 2019), and may release leachates that interfere with algal development (Dyer and Richardson 1962; Blankley 1973; Kerrison et al. 2017). This means that different sources of a particular polymer may give different results during cultivation trials (Dyer and Richardson 1962). In E1, we found differences in the sporophyte coverage between PES twine produced by two manufacturers. Also, in previous studies, solid PA was determined to be a highly suitable material for S. latissima cultivation due to a low $\theta_{\mathrm{w}}$ and strong bioadhesion (Kerrison et al. 2017, 2018, 2019). Yet, in the present study, PA twine was equally successful to PP twine, which has a weak bioadhesion with S. latissima. We hypothesise that this may be due to the inclusion of plasticizers within the PA twine to make it more flexible, based on a similar difference observed between solid and flexible polyvinylchloride (Kerrison unpublished results).

Our present study also reports that the development rate of S. latissima was slowed on PA in E1 and PVA in E2, yet this was not consistent between experiments and was not seen in previous studies on S. latissima (Kerrison et al. 2017, 2019). These differences may be due to an inefficiency of precleaning the twine using $2 \% \mathrm{NaHCO}_{3}$ method. During textile manufacture, spinning oils or waxes are added to lubricate the strands. These and any other dirt/surface leachate should be fully removed to prevent any negative impact on the attachment or development of macroalgal juveniles. For future work, we recommend the use of boiling or strong detergent as used in previous studies where no negative effects were reported (Salinas et al. 2006; Shea and Chopin 2007; Edwards and Watson 2011; Kerrison et al. 2017).

\section{Favoured twisted twine}

The structural form of the twine - twisted or braided - had a surprisingly large impact on juvenile development and the final yield. When three-stranded 2-mm twine is wound onto a surface, the surface topography varied by $\sim 1 \mathrm{~mm}$ between prominent and recessed regions. When meiospores were seeded onto this surface, sporophytes tended to only develop on the prominent regions. This reduced the effective growing area of the twine, causing a lower density and coverage of juvenile sporophytes after 4 or 5 weeks, respectively. In contrast, sporophytes on braided twine had a similar density and coverage to the glass control; this may be because the hollow structure of braided twine flattens when wound against the surface.

These findings alone would suggest that braided twine is a superior choice, as concluding by Salinas et al. (2006) for Undaria pinnatifida and S. latissima. Nonetheless, following outplanting, the opposite result is seen: twisted twine produced 25\% more biomass than braided. We identify three factors that may be responsible. First, the flat topography of braided twine reduces the opportunities for early thigmotactic interaction compared with the twisted twine. Second, the flat form of braided twine will have increased the likelihood that when unreeled onto the longline, the seeded side of the twine will lie pressed against the rope, creating denuded areas of longline. Third, twisted twine can be wrapped more closely around the longline and has greater elasticity; braided twine tends to sag away from the longline preventing holdfast attachment to the carrier rope (pers. obs).

When seeding sporophytes onto twine using the binder method (Kerrison et al. 2018b), twisted twine allowed a higher density of sporophyte to develop, compared to braided twine or glass. The more varied topography of the twisted twine provides recesses where the binder carrying the sporophytes can become trapped (Kerrison et al. 2018b). These recesses may also protect the binder from being washed away, allowing a higher density of sporophytes to become attached.

In summary, these findings indicate that twisted twine should be used in favour of braided during the seeding of any development stage. The topography of the twisted form provides more opportunity for early thigmotactic attachment, provides recesses that aid binder-seeding and wraps more favourable around the longline rope.

\section{Natural fibres}

The selection of a renewable biodegradable polymer for seaweed cultivation is highly favourable to prevent microplastic 
release from the cultivation structures (Wright et al. 2013). Lignocellulose fibres of sisal and jute biodegrade in seawater (Holt 1984; Winger et al. 2015) may be a substitute for nonbiodegradable plastics. To this end, we examined the suitability of three materials as seeding twines for S. latissima cultivation: sisal, jute and cotton.

Both sisal and jute were highly unsuitable when seeded with meiospores. Very few surviving sporophytes were observed after 6 weeks, despite a dense initial meiospore settlement. This agrees with some preliminary work by Holt (1984), where a similar toxic/developmental inhibition effect on kelp meiospore was reported. Leaching compounds are thought to be responsible, as aqueous extract from dried sisal and jute reduce seed germination and growth in some higher plants (Chowdhury et al. 2009). Nevertheless, it should be noted that other macroalgae are unaffected by this leachate (Geng et al. 2015; Le et al. 2018) and so sisal or jute may only be toxic to specific species or groups.

Another natural lignocellulose-palm fibre-has been used traditionally in China. The sap is known to be toxic to juvenile kelps, causing growth malformations or killing them outright (FAO 1989, 2004). To prevent this, the fibres are extensively treated beforehand involving: ageing, dry and wet hammering, re-boiling, washing, and finally, sun drying (FAO 2004). It is likely that the toxic leachate from sisal or jute can be removed by a similar process; nevertheless, synthetic twines are likely to be favoured since they provide consistent qualities and require less pre-treatment.

Despite the apparent toxicity of jute and sisal towards meiospores, binder-seeding with sporophytes was successful, with no toxicity or developmental inhibition observed. The rough texture allowed a higher density of juveniles to become establish compared to the control. However, the attachment force was far below on PVA, and so jute and sisal are not recommended as a suitable substitute for synthetic twine.

Cotton is a component of the standard twine used for kelp cultivation in China (Pang et al. 2009). In this study, it initially appeared unsuitable for meiospore seeding, with slow growth and low density indicating a possible moderate toxic effect. Despite this, after cultivation at sea, the yield of cotton was equivalent to the best synthetic twine, PVA. When binder-seeding sporophytes onto cotton, the density of established sporophytes was higher than on most synthetic twines. In addition, the attachment force was high, equivalent to PVA. These results may be explained by cotton's physical structure, which is composed of numerous hollow cellulose fibres of $\Phi$ 11-22 $\mu \mathrm{m}$ (Cotton Inc. 2018). These form a very fluffy surface structure with excellent water retaining properties. In the case of binderseeding with sporophytes, this complex structure enmeshed the binder and provided the sporophyte holdfast with numerous attachment points and early thigmotactic attachment. This makes cotton an excellent option when binder-seeding sporophytes.

\section{Surface topographic complexity}

Increasing twine surface roughness by sanding is known to improve the retention of spray-seeded gametophytes, which physically entangled in the more fluffy structure (Salinas et al. 2006). However, the very fluffy surface of the cotton was detrimental to seeded meiospores, probably because this increases the boundary layer thickness, so reducing the refreshment rate of nutrients and dissolved gases, slowing development. These results highlight that increased surface complexity of the twine is beneficial up until a tipping point where the structure becomes too open and slows the early development due to an increased boundary layer thickness. It is possible to control the degree of fluffiness in cotton textiles, and so, a less fluffy cotton twine may be an excellent biodegradable twine.

\section{Corona treatment}

The surface modification of polymers using corona is an effective method to improve the bioadhesive attachment of S. latissima (Kerrison et al. 2019). The high frequency electrical discharge from corona alters the chemical and microtopographical structure creating new polar bonding points and lowering the $\theta_{\mathrm{w}}$ (Strobel et al. 2003; Kang and Neoh 2009). In this study, corona treatment leads to a substantial improvement of $15-34 \%$ in the final yield achieved from twine of PA, PES and PP, making them similar to the yield of $4.7 \pm 0.5 \mathrm{~kg}$ achieved by PVA. By improving bioadhesive attachment using corona surface treatment will reduce the detachment of juveniles due to physical abrasion during deployment or agitation during storms, thus allowing the maximal yield to be achieved. No yield improvement was seen on corona-treated PVA, which already provides a strong bioadhesive attachment (Kerrison et al. 2019). Corona or other surface modification treatment may be a cost-effective way to 'upgrade' cheap polymers such as PP, into excellent twines for seaweed cultivation (Kerrison et al. 2019).

\section{Conclusions}

Through an experimental approach combining both hatchery and outplanting phase experimentation, we have determined that the characteristics of the settlement twine can influence the development of Saccharina latissima juveniles.

The main findings were: 
1. Twisted twine performed better than braided, for both meiospore and sporophyte seeding.

2. PA, PES and PP twine gave a lower final yield than PVA, due to weaker bioadhesion of juveniles.

3. Corona treatment of PA, PES and PP twine improved the final yield, equalling that of PVA.

4. Jute and sisal were toxic to meiospores. These materials were successful when sporophyte seeding, but bioadhesion was weak.

5. Fluffy cotton twine, slowed the growth of meiospores, yet the yield and bioadhesive force were equivalent to PVA. Less fluffy cotton may be highly suitable as a biodegradable twine.

Funding information Funding for this work was provided by the European Commission Community Research and Development Information Service (CORDIS) Seventh Framework Programme (FP7) project-Advanced Textiles for Open Sea Biomass Cultivation (AT SEA) grant no. 280860.

\section{Compliance with ethical standards}

Conflict of interest The authors declare that they have no conflict of interest.

Open Access This article is distributed under the terms of the Creative Commons Attribution 4.0 International License (http:// creativecommons.org/licenses/by/4.0/), which permits unrestricted use, distribution, and reproduction in any medium, provided you give appropriate credit to the original author(s) and the source, provide a link to the Creative Commons license, and indicate if changes were made.

\section{References}

Anderson TW, Darling DA (1952) Asymptotic theory of certain "goodness of fit" criteria based on stochastic processes. Ann Math Stat 23:193-212

Bak UG, Mols-Mortensen A, Gregersen O (2018) Production method and cost of commercial-scale offshore cultivation of kelp in the Faroe Islands using multiple partial harvesting. Algal Res 33:36-47

Bitton R, Ben-Yehuda M, Davidovich M, Balazs Y, Potin P, Delage L, Colin C, Bioanco-Peled H (2006) Structure of algal-born phenolic polymeric adhesives. Macromol Biosci 6:737-746

Blankley WF (1973) Toxic and inhibitory materials associated with culturing. In: Stein JR (ed) Handbook of phycological methods. Culture methods and growth measurements. Cambridge University Press, Cambridge, pp 207-229

Bleakley S, Hayes M (2017) Algal proteins: extraction, application, and challenges concerning production. Foods 6:33

Candries M, Anderson CD, Atlar M (2001) Foul release systems and drag. Consolidation of technical advances in the protective and marine coatings industry. Proc PCE 2001 Conf Antwerp:273-286

Chowdhury H, Saha AR, Sarkar SK, Tripathi MK (2009) Allelopathic effects of jute (Corchorus capsularis and C. olitorius) and sisal (Agave sisalana) leaf leachates on rice (Oryza sativa), wheat (Triticum aestivum) and greengram (Vigna radiata). Indian J Agric Sci 79:624-627

Cotton Inc (2018) Cotton morphology and chemistry. http://www. cottoninccom/product/NonWovens/Nonwoven-Technical-Guide/ Cotton-Morphology-And-Chemistry. Accessed 1 Jan 2018
Deanin RD (1975) Additives in plastics. Environ Health Perspect 11:3539

Druehl LD, Baird R, Lindwall A, Lloyd KE, Pakula S (1988) Longline cultivation of some Laminariaceae in British Columbia, Canada. Aquac Fish Manag 19:253-263

Dyer DL, Richardson DE (1962) Materials of construction in algal culture. Appl Microbiol 10:129-131

Edwards M, Watson L (2011) Aquaculture explained no. 26: Cultivating Laminaria digitata. Irish Sea Fisheries Board

FAO (1989) Culture of kelp (Laminaria japonica) in China. Training manual 89/6 (RAS/86/024). www.fao.org/docrep/field/003/ab724e/ AB724E00.htm\#TOC. Accessed 20 May 2004

FAO (2004) Cultured aquatic species information programme: Laminaria japonica (Areschoug, 1851). www.fao.org/fishery/culturedspecies/ Laminaria_japonica/en,. Accessed 1 Apr 2016

Finlay JA, Callow ME, Schultz MP, Swain GW, Callow JA (2002) Adhesion strength of settled spores of the green alga Enteromorpha. Biofouling 18:251-256

Forbord S, Skjermo J, Arff J, Handå A, reitan KI, Bjerregard R, Lüning KL (2012) Development of Saccharina latissima (Phaeophyceae) kelp hatcheries with year-round production of zoospores and juvenile sporophytes on culture ropes for kelp aquaculture. J Appl Phycol 24:393-399

Geng H, Yan T, Zhou M, Liu Q (2015) Comparative study of the germination of Ulva prolifera gametes on various substrates. Estuar Coast Shelf Sci 163:89-95

Gewert B, Ogonowski M, Barth A, MacLeod M (2017) Abundance and composition of near surface microplastics and plastic debris in the Stockholm archipelago, Baltic Sea. Mar Pollut Bull 120:292-302

Holdt SL, Kraan S (2011) Bioactive compounds in seaweed: functional food applications and legislation. J Appl Phycol 23:543-597

Holt TJ (1984) The development of techniques for the cultivation of Laminariales in the Irish Sea. University of Liverpool, Port Erin, Isle of Man

Huggett MJ, Nedved BT, Hadfield MG (2009) Effects of initial surface wettability on biofilm formation and subsequent settlement of Hydroides elegans. Biofouling 25:387-399

Hughes AD, Kelly MS, Black KD, Stanley MS (2012) Biogas from macroalgae: is it time to revisit the idea? Biotechnol Biofuels 5:86

Kang ET, Neoh KG (2009) Surface modification of polymers. In: Herman FM (ed) Encyclopedia of polymer science and technology, p 12344

Kawachi M, Noël M-H (2005) Sterilisation and sterile technique. In: Andersen RA (ed) Algal culturing techniques. Elsevier Academic Press, London, pp 65-82

Kerrison PD, Stanley MS, Kelly M, MacLeod A, Black KD, Hughes AD (2016) Optimising the settlement and hatchery culture of Saccharina latissima (Phaeophyta) by manipulation of growth medium and substrate surface condition. J Appl Phycol 28:1181-1191

Kerrison PD, Stanley MS, Black KD, Hughes AD (2017) Assessing the suitability of twelve polymer substrates for the cultivation of macroalgae Laminaria digitata and Saccharina latissima (Laminariales). Algal Res 22:127-134

Kerrison P, Stanley MS, Mitchell E, Cunninham L, Hughers AD (2018a) A life-stage conflict of interest in kelp: higher meiospore settlement where sporophyte attachment is weak. Algal Res 35:309-318

Kerrison PD, Stanley MS, Hughes AD (2018b) Textile substrate seeding of Saccharina latissima sporophytes using a binder: an effective method for the aquaculture of kelp. Algal Res 33:352-357

Kerrison PD, Stanley MS, De Smet D, Buyle G, Hughes AD (2019) Holding (not so) fast: surface chemistry constrains kelp bioadhesion. Eur J Phycol 1-9. https://doi.org/10.1080/09670262.2018.1547924

Kraan S (2013) Mass-cultivation of carbohydrate rich macroalgae, a possible solution for sustainable biofuel production. Mitig Adapt Strateg Glob Chang 18:27-46 
Kuraway (2015) Kuralon. www.sp-paper.jp/english/product/vinylon. html. www.sp-paper.jp/english/product/vinylon.html. Accessed 15 Jan 2015

Le HN, Hughes AD, Kerrison PD (2018) Early development and substrate twine selection for the cultivation of Sargassum muticum (Yendo) Fensholt under laboratory conditions. J Appl Phycol 30: 2475-2483

Levene H (1960) Robust tests for equality of variances. In: Olkin I (ed) contributions to probability and statistics: essays in honor of Harold Hotelling. Stanford University Press, Palo Alto, pp 278-292

Milligan KLD, DeWreede RE (2000) Variations in holdfast attachment mechanics with developmental stage, substratum-type, season, and wave-exposure for the intertidal kelp species Hedophyllum sessile (C. Agardh) Setchell. J Exp Mar Biol Ecol 254:189-209

Pang SJ, Liu F, Shan TF, Gao SQ, Zhang ZH (2009) Cultivation of the brown alga Sargassum horneri: sexual reproduction and seedling production in tank culture under reduced solar irradiance in ambient temperature. J Appl Phycol 21:413-422

Peteiro C, Freire Ó (2011) Offshore cultivation methods affects blade features of the edible seaweed Saccharina latissima in a bay of Galicia, Northwest Spain. Russ J Mar Biol 37:319-323

Peteiro C, Sánchez N, Dueñas-Liaño C, Martínez B (2014) Open-sea cultivation by transplanting young fronds of the kelp Saccharina latissima. J Appl Phycol 26:519-528

Rittschof D, Costlow JD (1989) Bryozoan and barnacle settlement in relation to initial surface wettability: a comparison of laboratory and field studies. Sci Mar 53:411-416

Salgado LT, Cinelli LP, Viana NB, de Carvalho T, Mourao DS, Teixeira VL, Farina M, Filho AG (2009) A vanadium bromoperoxidase catalyzes the formation of high-molecular-weight complexes between brown algal phenolic substances and alginates. J Phycol 45:193-202

Salinas JM, Cremades J, Peteiro C, Fuertes C (2006) Influencia de las características del hilo de siembra en el cultivo experimental de Undaria pinnatifida (Harvey) Suringar y Laminaria saccharina
(L.) Lamouroux (Laminariales, Phaeophyta). Bol Inst Esp Oceanogr 22:65-72

Sanderson JC, Dring MJ, Davidson K, Kelly MS (2012) Culture, yield and bioremediation potential of Palmaria palmata (Linnaeus) Weber \& Mohr and Saccharina latissima (Linnaeus) C.E. Lane, C. Mayes, Druehl \& G.W. Saunders adjacent to fish farm cages in Northwest Scotland. Aquaculture 354-355:128-135

Shea R, Chopin T (2007) Effects of germanium dioxide, an inhibitor of diatom growth, on the microscopic laboratory cultivation stage of the kelp, Laminaria saccharina. J Appl Phycol 19:27-32

Strobel M, Jones V, Lyons CS, Ulsh M, Kushner MJ, Dorai R, Branch MC (2003) A comparison of corona-treated and flame-treated polypropylene films. Plasmas Polym 8:61-95

Süzer S, Argun A, Vatansever O, Aral O (1999) XPS and water contact angle measurements on aged and corona-treated PP. J Appl Polym Sci 74:1846-1850

Vogel S (1996) Life in moving fluids. The physical biology of flow, 2nd edn. Princeton University Press, Princeton

Werner A, Dring MJ (2011) Aquaculture explained no. 27: cultivating Palmaria palmata. Bord Iascaigh Mhara

Winger PD, Legge G, Batten C, Bishop G (2015) Evaluating potential biodegradable twines for use in the snow crab fishery off Newfoundland and Labrador. Fish Res 161:21-23

Wright SL, Thompson RC, Galloway TS (2013) The physical impacts of microplastics on marine organisms: a review. Environ Pollut 178: $483-492$

Publisher's note Springer Nature remains neutral with regard to jurisdictional claims in published maps and institutional affiliations. 